\title{
INTERTEXTUALIDADE NA REDAÇÃO DO ENEM: UMA REFLEXÃO SOBRE A COMPETÊNCIA CINCO
}

\author{
Samarah Regia de Souza1
}

Orientadora: Profa. Dra. Ormezinda Maria Ribeiro

Artigo apresentado como requisito parcial para conclusão do curso de graduação em Letras Português Licenciatura.

Brasília, 2017.

1 Graduanda em Letras - Português Licenciatura pela Universidade de Brasília. samarahsouza.89@gmail.com 


\title{
INTERTEXTUALIDADE NA REDAÇÃO DO ENEM: UMA REFLEXÃO SOBRE A COMPETÊNCIA CINCO
}

SOUZA, Samarah Regia de ${ }^{1}$

\section{RESUMO}

O presente artigo se trata do critério avaliativo da prova de redação do Exame Nacional do Ensino Médio (ENEM), especialmente a competência cinco, que solicita ao candidato uma proposta de intervenção acerca do problema abordado. O objetivo é compreender a maior dificuldade dos participantes nesse critério - por meio de uma pesquisa de campo -, bem como intervir na forma como se pode conseguir atingir êxito em tal critério avaliativo, com base na dimensão política do ENEM. Serão apresentados e discutidos a história do exame nacional, os critérios e também seus eixos temáticos: educação; meio ambiente; direitos humanos; justiça social; ética social e direitos da criança e do adolescente. Em adição a isso, vale ressaltar a intertextualidade como fator crucial na elaboração da proposta de intervenção inovadora e detalhada.

Palavras-chave: ENEM; competência cinco; intertextualidade; eixos temáticos.

\begin{abstract}
This article is about the evaluation criterion of the writing test of the Exame Nacional do Ensino Médio (ENEM), especially the fifth competency, which demands the candidate to propose intervention on the approached problem. The objective is to understand the greater difficulty of the participants in this criterion by means of a field research - and to intervene in the way in which it is possible to be successful in such evaluation criterion, based on the political dimension of the ENEM. The history of the national examination, the criteria and also its thematic axes will be presented and discussed: education; environment; human rights; social justice; social ethics and the rights of children and adolescents. In addition to this, it is worth emphasizing the intertextuality as a crucial factor in the elaboration of the innovative and detailed intervention proposal.
\end{abstract}

Keywords: ENEM; fifth competence; intertextuality; thematic axes.

\section{INTRODUÇÃO}

Nota máxima na redação do Exame Nacional do Ensino Médio (ENEM) é o que muitos candidatos almejam, vista a sua dimensão. No contexto presente, esse exame é útil para vários fins e a redação é a única prova em que é possível o participante tirar 
nota mil, ou seja, muitas vezes, a maior etapa discursiva do ENEM garante uma nota alta no resultado final e, como consequência, a aprovação.

Contudo, não se trata de uma etapa fácil. Pelo contrário, escrever um texto dissertativo-argumentativo de apenas 30 linhas pode ser um dos maiores desafios. Nesse contexto, este artigo analisa essas dificuldades, com foco na competência cinco - a qual exige a elaboração de uma intervenção acerca do problema abordado - e busca propor sugestões para que os candidatos tenham melhor desempenho na prova de redação e também a fim de que professores possam auxiliar melhor seus alunos nessa questão.

Para tanto, será apresentada uma pesquisa de campo, com perguntas abertas e fechadas, sobre as dificuldades na competência cinco, além de observações sobre os eixos temáticos do ENEM, com base nos temas anteriores e na importância da intertextualidade na prova de redação.

A motivação para a elaboração deste artigo surgiu da minha experiência em sala de aula. Após observar meus alunos, assim como seus obstáculos na hora de escrever um texto, resolvi discorrer sobre os maiores desafios na prova do ENEM, com foco na competência cinco, na qual eles tiraram nota menor, com o propósito de intervir, com os métodos que utilizo nas minhas aulas para facilitar o processo da escrita.

\section{DESENVOLVIMENTO}

\subsection{A história do ENEM e sua dimensão política}

O Exame Nacional do Ensino Médio (ENEM) trata-se de uma avaliação de inciativa do Ministério da Educação do Brasil, criada em 1998. A prova tem vários fins atualmente, mas inicialmente servia apenas para avaliar o ensino médio brasileiro. Sua principal utilidade é no acesso ao ensino superior em universidades públicas brasileiras, por intermédio do Sistema de Seleção Unificada (SiSU). Segundo dados do Instituto Nacional de Estudos e Pesquisas Educacionais Anísio Teixeira (Inep), em sua primeira aplicação, o ENEM contou com 116 mil inscritos e em 2015 esse número aumentou para mais 9 milhões.

Outra possível utilidade do exame é garantir o acesso a universidades particulares, por meio do Programa Universidade para Todos (ProUni), com bolsas integrais ou parciais, e do Financiamento Estudantil (Fies). Foi a partir de 2009 que o ENEM também serviu como certificação de conclusão do ensino médio em cursos de Educação de Jovens e Adultos (EJA). 
A prova acontece em dois dias, sendo a redação aplicada no $2^{\circ}$ dia. O tipo de texto exigido é o dissertativo-argumentativo, sobre um tema social, científico, cultural ou político. O candidato deve defender uma tese com argumentos consistentes, coesos e coerentes na variedade padrão da Língua Portuguesa. No texto, o candidato deve elaborar proposta de intervenção social para o problema desenvolvido, tomando cuidado para sempre respeitar os direitos humanos.

Acerca dos possíveis temas da prova de redação, podem-se analisar, com os exames anteriores presentes na tabela abaixo, os eixos temáticos exigidos: educação, meio ambiente, direitos humanos, direitos da criança e do adolescente, ética social e justiça social. Esse leque de possibilidades sobre o tema permite aos candidatos uma reflexão sobre os problemas do cenário social contemporâneo, principalmente do Brasil.

Todos os anos, devido à repercussão do exame, o tema da redação ganha destaque nas notícias sobre a prova. Dessa maneira, é discutido não apenas pelos candidatos, mas também pela mídia, por internautas, professores, etc. Tal fato decerto evidencia a responsabilidade social do exame, visto que temas como "A persistência da violência contra a mulher na sociedade brasileira" (ENEM 2015) impulsionam reflexões as quais podem levar à intervenção e consciência social acerca da realidade brasileira.

\begin{tabular}{|c|c|c|}
\hline ANO & TEMA & VIÉS \\
\hline 2005 & $\begin{array}{l}\text { O TRABALHO INFANTIL NA SOCIEDADE } \\
\text { BRASILEIRA } \\
\text { O PODER DE TRANSFORMAÇÃO DA } \\
\text { LEITURA }\end{array}$ & $\begin{array}{c}\text { DIREITOS DA CRIANÇA } \\
\text { E DO ADOLESCENTE } \\
\text { EDUCAÇÃO }\end{array}$ \\
\hline 2007 & $\begin{array}{l}\text { O DESAFIO DE SE CONVIVER COM AS } \\
\text { DIFERENÇAS }\end{array}$ & DIREITOS HUMANOS \\
\hline 2008 & $\begin{array}{l}\text { COMO PRESERVAR A FLORESTA } \\
\text { AMAZÔNICA? }\end{array}$ & MEIO AMBIENTE \\
\hline 2009 & $\begin{array}{l}\text { O INDIVÍDUO FRENTE À ÉTICA } \\
\text { NACIONAL }\end{array}$ & ÉTICA SOCIAL \\
\hline 2010 & $\begin{array}{l}\text { O TRABALHO NA CONSTRUÇÃO DA } \\
\text { DIGNIDADE HUMANA }\end{array}$ & JUSTIÇA SOCIAL \\
\hline
\end{tabular}




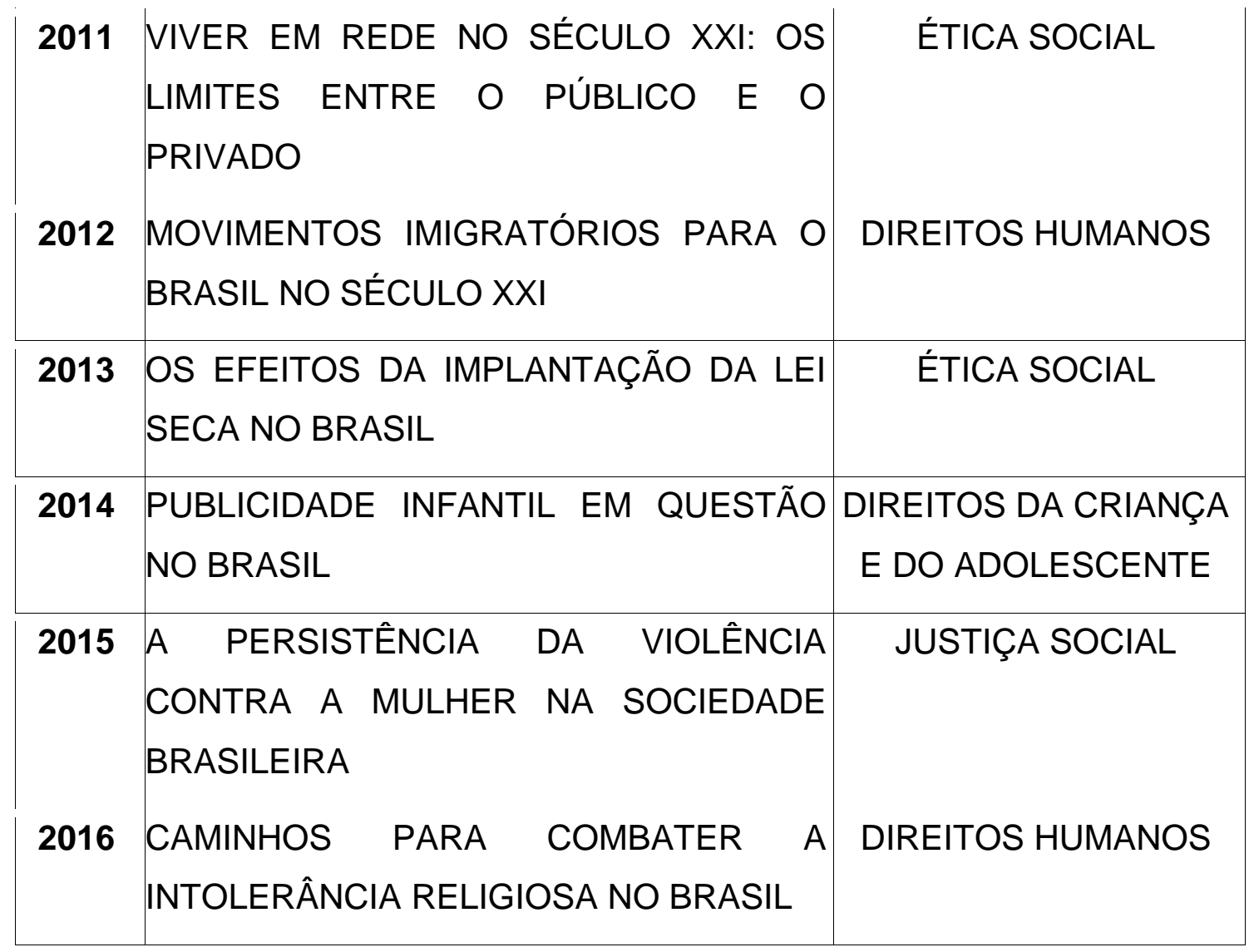

\subsection{A redação no ENEM: as 5 competências e como é feita a avaliação}

A redação do ENEM é avaliada em cinco competências:

\begin{tabular}{|c|c|}
\hline COMPETÊNCIAS & EXIGÊNCIAS \\
\hline 1 & $\begin{array}{l}\text { Demonstrar domínio da modalidade escrita formal da Língua } \\
\text { Portuguesa }\end{array}$ \\
\hline 2 & $\begin{array}{l}\text { Compreender a proposta de redação e aplicar conceitos das várias } \\
\text { áreas de conhecimento para desenvolver o tema, dentro dos limites } \\
\text { estruturais do texto dissertativo-argumentativo em prosa. }\end{array}$ \\
\hline 3 & $\begin{array}{l}\text { Selecionar, relacionar, organizar e interpretar informações, fatos, } \\
\text { opiniões e argumentos em defesa de um ponto de vista. }\end{array}$ \\
\hline 4 & $\begin{array}{l}\text { Demonstrar conhecimento dos mecanismos linguísticos necessários } \\
\text { para a construção da argumentação. }\end{array}$ \\
\hline 5 & Elaborar proposta de intervenção para o problema abordado, \\
\hline
\end{tabular}


Cada competência vale 200 pontos, logo, a nota final da redação é de 1.000 pontos. A avaliação é bem organizada, com habilidades em cada competência. Cada habilidade vale um subtotal, que diminui de quarenta em quarenta pontos. Ademais, a prova de redação é corrigida por dois professores e, caso haja discrepância nas notas, um terceiro corretor avalia a redação e a média das notas mais próximas será a nota final.

Tal avaliação, indubitavelmente, é eficiente, pois alinha o critério na equipe de correção, deixa-o objetivo, além de ser mais justo para o candidato. Assim, há também melhor entendimento do nível que o participante deve obter para atingir a nota máxima em cada competência.

\subsection{Proposta de intervenção: quais os requisitos?}

Como o foco deste artigo é a quinta competência, cabe explorar as habilidades da proposta de intervenção:

\begin{tabular}{|c|l|}
\hline 200 pontos & $\begin{array}{l}\text { Elabora muito bem proposta de intervenção, de forma detalhada, } \\
\text { relacionada ao tema e articulada à discussão desenvolvida no texto. }\end{array}$ \\
\hline 160 pontos & $\begin{array}{l}\text { Elabora bem proposta de intervenção relacionada ao tema e articulada à } \\
\text { discussão desenvolvida no texto. }\end{array}$ \\
\hline 120 pontos & $\begin{array}{l}\text { Elabora, de forma mediana, proposta de intervenção relacionada ao tema } \\
\text { e articulada à discussão desenvolvida no texto. }\end{array}$ \\
\hline 40 pontos & $\begin{array}{l}\text { Elabora, de forma insuficiente, proposta de intervenção relacionada ao } \\
\text { tema, ou proposta não articulada com a discussão desenvolvida no texto. }\end{array}$ \\
\hline 0 ponto & $\begin{array}{l}\text { Apresenta proposta de intervenção vaga ou apenas citada, precária ou } \\
\text { relacionada apenas ao assunto. } \\
\text { relacionada ao tema ou ao assunto. }\end{array}$ \\
\hline
\end{tabular}


Segundo a Cartilha do Participante Redação 2016, elaborada pela Diretoria De Avaliação Da Educação Básica (DAEB), os critérios avaliativos da competência cinco envolvem a consistência da proposta de intervenção. Conforme o texto presente na cartilha:

Ao redigir seu texto, procure evitar propostas vagas, gerais; busque propostas mais concretas, específicas, consistentes com o desenvolvimento de suas ideias. Antes de elaborar sua proposta, procure responder às seguintes perguntas: o que é possível apresentar como proposta de intervenção na vida social? Como viabilizar essa proposta? Seu texto será avaliado, portanto, com base na combinação dos seguintes critérios:

a) presença de proposta $x$ ausência de proposta; $e$

b) proposta com detalhamento dos meios para sua realização $\mathrm{x}$ proposta sem 0 detalhamento dos meios para sua realização. (Cartilha do participante ENEM 2016, página 25)

Nessa perspectiva, vale analisar e comparar a proposta de intervenção de uma redação que tirou nota máxima e uma que não alcançou nota máxima no certame de 2015, a fim de ilustrar esse critério avaliativo. O primeiro texto é da Cartilha do Participante e o segundo é de um ex-aluno que de bom grado enviou a mim sua redação e o espelho de correção para eu usar em sala de aula e neste artigo.

\section{TEXTO I}

"A história da humanidade é a história da luta..." das mulheres. Karl Marx, filósofo e sociólogo alemão, baseou seu pensamento na extinção gradual das classes sociais e das diferenças presentes na sociedade moderna. Analogamente, percebe-se, no âmbito das relações sociais humanas, a presença de um grupo que não foge à luta por seus direitos: a população feminina. Por viverem em um país patriarcal herança herdada dos tempos do Império - as mulheres brasileiras permanecem à deriva da sociedade. Levando isso em consideração, recebem maus tratos e são menosprezadas por homens e chefes de famílias.

Na ótica aristotélica, a mulher é concebida como a encarnação de um homem ruim. Este fato talvez justifique o alto índice de violência contra o espírito feminino em voga no Brasil, subjugado por homens e até mesmo mulheres que desrespeitam a igualdade do gênero. Segundo o Mapa da Violência de 2012, milhares de mulheres foram assassinadas, como também muitas delas sofreram com os mais diversos tipos de agressão, incluindo agressões de caráter físico, com predomínio de $51,68 \%$ dos casos.

Entretanto, existem movimentos e organizações que têm como compromisso a redução dos descasos com a figura da mulher, como a campanha contra o feminicídio, que une cidadãs em prol do 
combate ao patriarcalismo que impera na sociedade brasileira. Infelizmente, nem toda comunidade feminina se junta e segue esses princípios. Geralmente, as mulheres aceitam a dominação e, no viés de Max Weber, só há dominação se houver aceitação.

Não se deve esquecer que as atitudes femininas são sutis, levando-as a questionarem o poderio de uma denúncia a uma delegacia de polícia mais próxima. Portanto, com o intuito de atenuar os maus tratos e a submissão da mulher na contemporaneidade, cabe ao Estado a fiscalização da Lei Maria da Penha e também a aplicação da mesma com maior rigor. Além disso, é papel da sociedade a criação de fóruns de discussão sobre os direitos da mulher, inspirados em grandes figuras adeptas à valorização feminina, como Frida Kahlo e Simone de Beauvoir. Cabe à mídia a divulgação de casos de violência doméstica, via televisão e internet, que promoverão a conscientização da sociedade a respeito do quanto a mulher tem valor.

(Redação de Lucas Domingos Ribeiro, Cartilha do Participante ENEM 2016, p.57)

O texto acima utilizou vários mecanismos para alcançar a nota máxima. Primeiramente, sua intervenção teve total relação com o desenvolvimento, ou seja, manteve a coerência. Além disso, utilizou três agentes (Estado, sociedade e mídia), com mais de uma ação. Um fator que chama atenção nessa proposta de intervenção também é o fato de o candidato ter usado informações, intertextualidades, que vão além dos textos da proposta de redação, na composição da conclusão: Frida Khalo e Simone de Beauvoir. Logo, percebe-se que seguiu os critérios de detalhamento exigidos pela banca. 


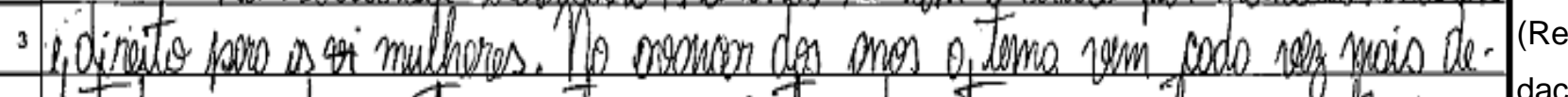

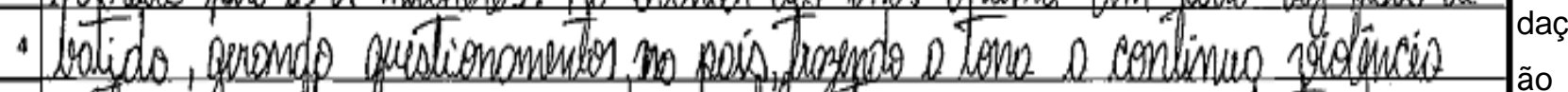

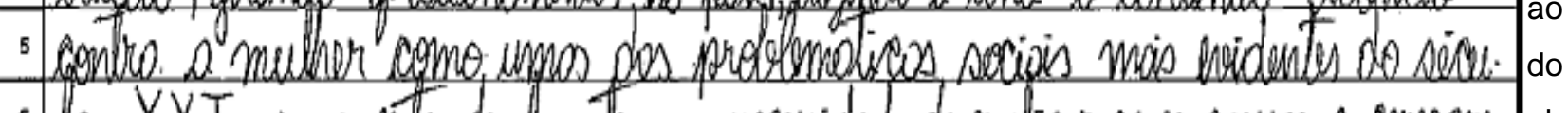

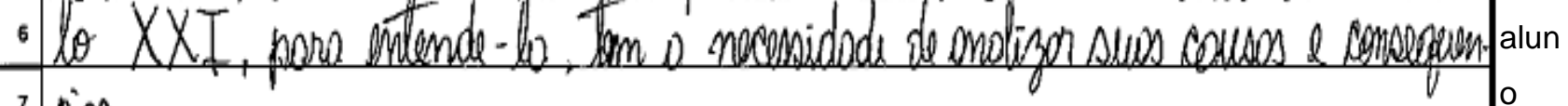
7 cins.

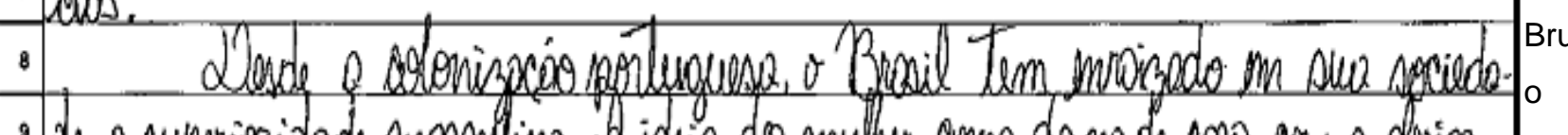

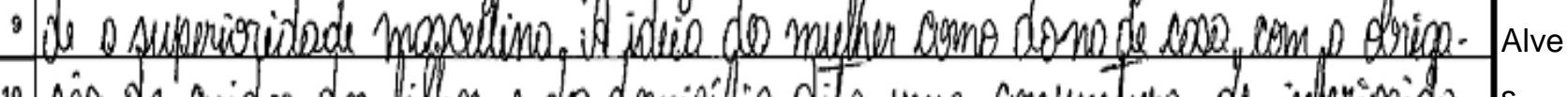

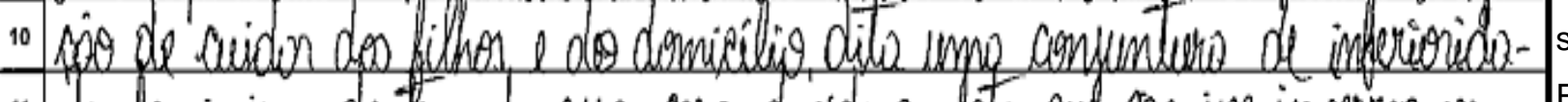

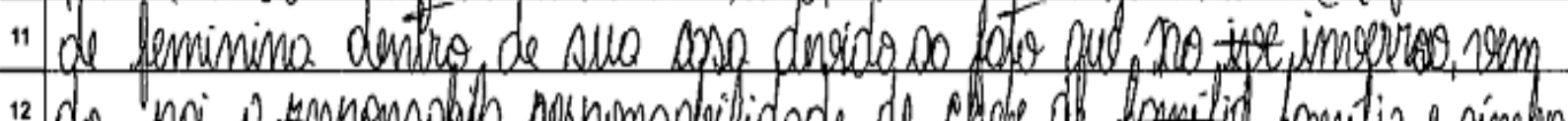

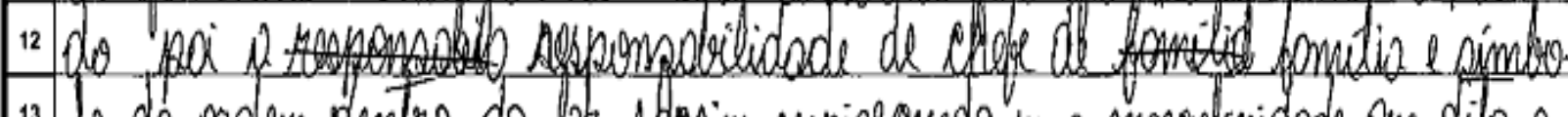

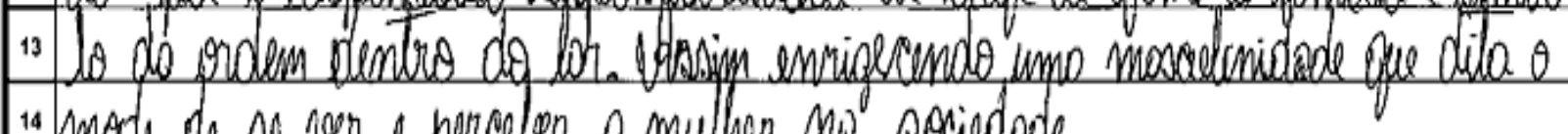

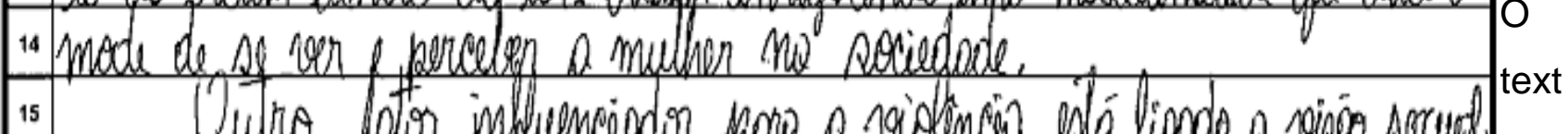

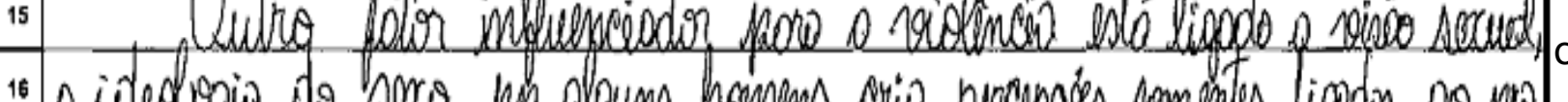

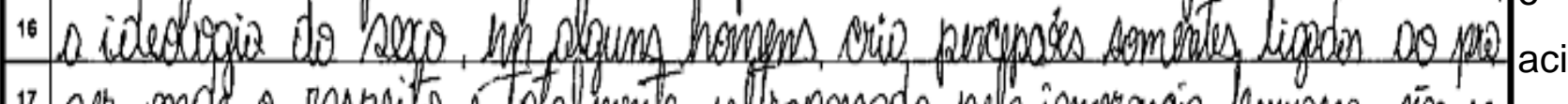

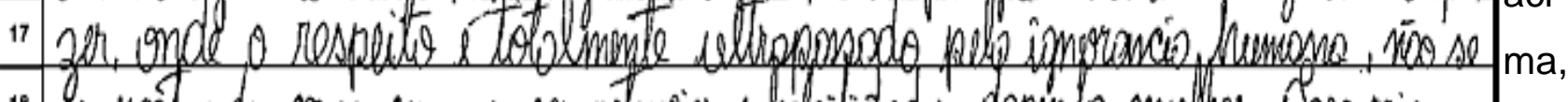

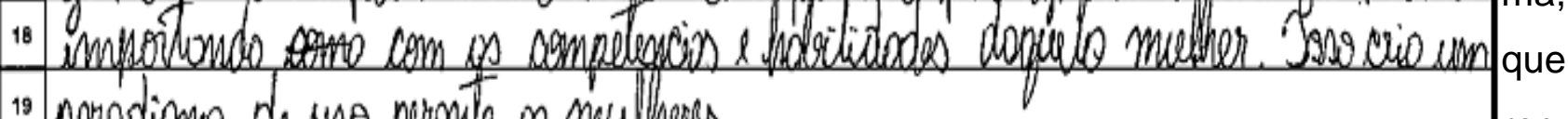

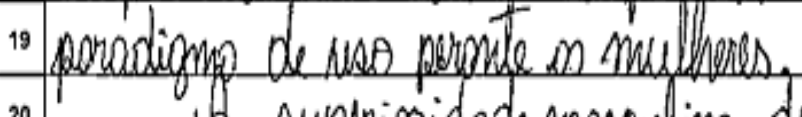

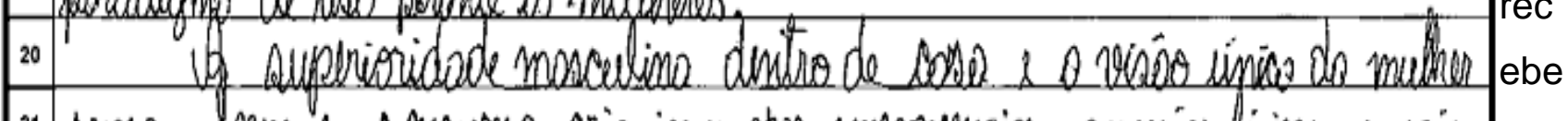

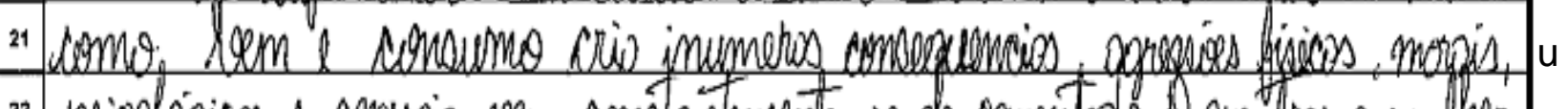

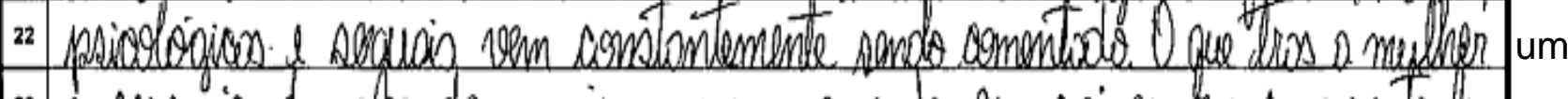

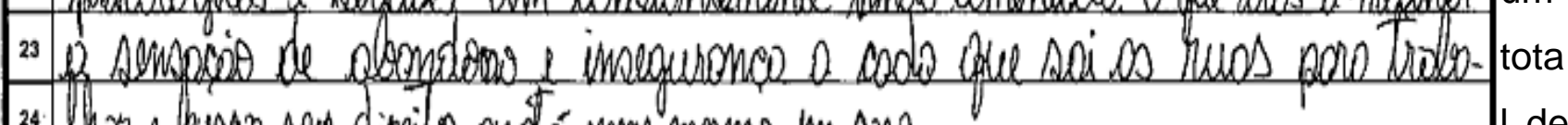

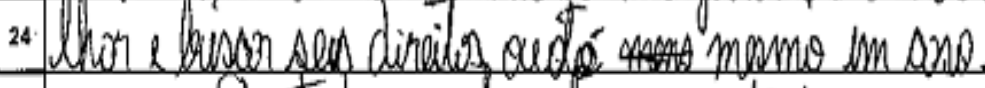

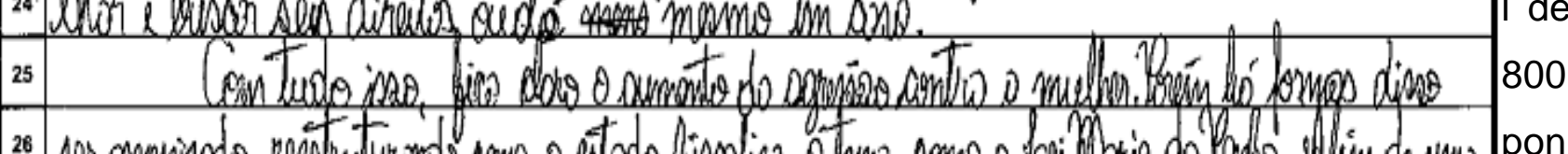

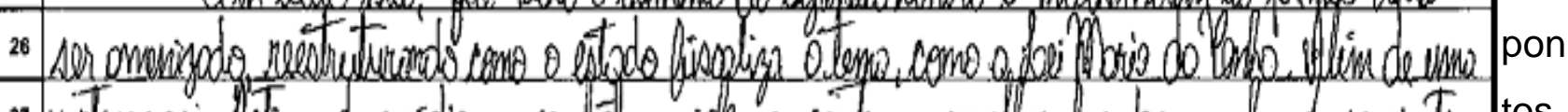

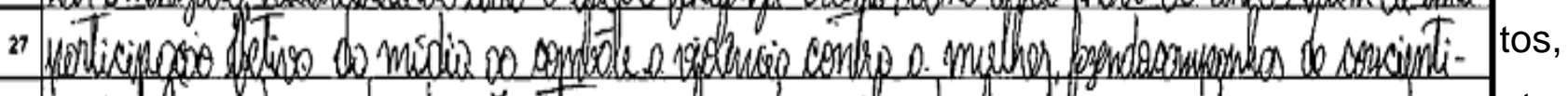

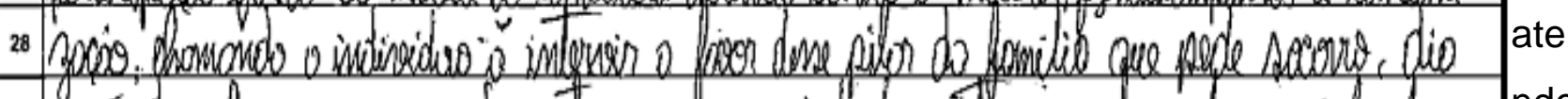

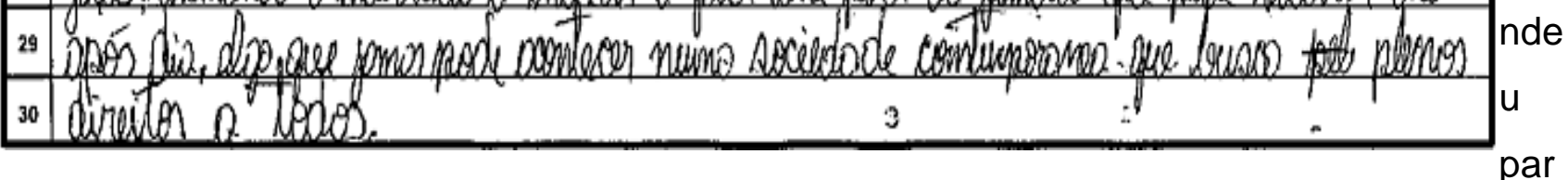
cialmente aos critérios da banca. Apesar de existir uma problematização pertinente, o texto carece de consistência argumentativa, visto que foram apresentados argumentos 
sem comprovação, como no terceiro parágrafo, em que escreveu sobre a visão sexualizada da mulher como causa da violência contra o gênero feminino, no entanto nenhum exemplo foi utilizado.

Quanto ao foco do artigo, faltou na intervenção detalhamento das ações e dos agentes. Por exemplo, como ação apenas foi citada a fiscalização, mas não houve identificação específica do órgão que realizaria essa ação.

Em contraste com o texto nota mil, esse texto perde 200 pontos pela falta de intertextualidade, fator crucial na consistência argumentativa. Logo, é perceptível a carência de leitura sobre o assunto, para citar argumento de autoridade, por exemplo.

O dialogismo de Mikhail Bakhtin está diretamente relacionado a essa questão de intertextualidade. Dialogismo consiste em uma interação de textos, ou seja, um texto não é visto de forma isolada, mas sim relacionado a outras produções textuais semelhantes. Nesse sentido, na redação do ENEM, é impossível adquirir nota máxima com a ausência de outras referências textuais, ainda mais na competência cinco, que exige do candidato detalhamento na proposta de intervenção do problema abordado.

Fiorin (2006, p.19), explica melhor esse conceito de dialogismo ao afirmar que "[...] o enunciador, para constituir um discurso, leva em conta o discurso de outrem, que está presente no seu. Por isso, todo discurso é inevitavelmente ocupado, atravessado pelo discurso alheio." Nesse viés, relacionado à produção textual, o dialogismo é referente à intertextualidade, ou seja, para produzir um texto dissertativo-argumentativo de fato consistente, o candidato deve fazer correlação entre seu texto e o texto de outros autores.

Foi a francesa Julia Kristeva que, a partir do dialogismo bakhitiniano, criou o conceito de intertextualidade. Segundo Kristeva (1966), se um leitor reconhecer outro autor no texto que está lendo, ocorrerá a intertextualidade, visto que haverá, então, relação entre os dois textos.

Regina Frasson em "A intertextualidade como recurso de argumentação" (1992, p.89) escreveu que "[...]Cada obra surge como uma nova voz (ou um novo conjunto de vozes), que fará soar diferentemente as vozes anterior, arrancando-lhe novas entonações". Nesse sentido, o fato de escolher um argumento de autoridade já demonstra a opinião de quem está escrevendo o texto, ou seja, intertextualidade vai além de apenas um texto dentro do outro, pois também significa posicionamento.

\section{Dificuldades em elaborar a proposta de intervenção}


Mas, afinal, por que os alunos ainda carecem de bagagem cultural para demonstrar repertório sociocultural diverso em um texto dissertativo-argumentativo? Para entender tal fato, vale analisar os resultados de uma pesquisa de campo, um questionário entregue a candidatos do ENEM 2016. A pesquisa buscou coletar informações acerca de uma das maiores dificuldades na prova de redação do Enem, com foco na competência cinco, exigida na avaliação da prova, a fim de se selecionar o que os candidatos elegem como o mais difícil na hora de escrever a proposta de intervenção e o porquê dessa dificuldade, para que, após o entendimento das opiniões dos participantes, o objetivo do artigo compreender a dificuldade dos candidatos nessa competência e intervir em melhores métodos de ensino nessa área - fosse alcançado. O público-alvo foram pessoas que estavam prestando e/ou já prestaram o ENEM. No questionário, há perguntas abertas e fechadas, pois a pesquisa é quantitativa e qualitativa.

Foram entrevistados 31 candidatos. Começando com as perguntas fechadas, cabe fazer análise dos resultados, por meio da tabulação, sendo " $Q$ " a quantidade de indivíduos:

\section{Pergunta 1}

Assinale seu nível de dificuldade com os critérios avaliativos da redação do ENEM. Você considera a prova de redação:

\begin{tabular}{|l|l|l|}
\multicolumn{1}{|c|}{$\begin{array}{c}\text { Fatores de } \\
\text { escolha }\end{array}$} & \multicolumn{1}{|c|}{$\mathbf{Q}$} & \multicolumn{1}{c|}{$\%$} \\
\hline Fácil & 0 & $0 \%$ \\
\hline $\begin{array}{l}\text { Apenas } \\
\text { trabalhosa }\end{array}$ & 24 & $77,5 \%$ \\
\hline Difícil & 7 & $22,5 \%$ \\
\hline Muito difícil & 0 & $0 \%$ \\
\hline $\begin{array}{l}\text { Total de } \\
\text { respostas }\end{array}$ & 31 & $100 \%$ \\
\hline
\end{tabular}

A maioria considera a prova de redação apenas trabalhosa. Isso significa que a maioria sente necessidade de se esforçar um pouco mais na prova de redação, mas não se sente incapaz de realizá-la. As alternativas "fácil" e "muito difícil" não foram assinaladas. A segunda maior assinalada foi "difícil". Nas respostas das próximas questões, pode-se perceber em que consiste a dificuldade maior dos candidatos. 


\section{Pergunta 2}

Para se obter nota máxima na Competência 5, segundo a Cartilha de Redação do Enem 2016, o candidato deve chegar a este nível: "Elabora muito bem proposta de intervenção, de forma detalhada, relacionada ao tema e articulada à discussão desenvolvida no texto". Em que parte dessa habilidade você costuma ter mais dificuldade na hora de escrever a intervenção?

\begin{tabular}{|l|l|l|}
\hline \multicolumn{1}{|c|}{ Fatores de escolha } & Q & $\%$ \\
\hline Elaborar uma proposta de intervenção, mesmo que não seja detalhada & 2 & $6,5 \%$ \\
\hline $\begin{array}{l}\text { Relacionar a proposta de intervenção ao tema e à discussão desenvolvida } \\
\text { no texto }\end{array}$ & 2 & $6,5 \%$ \\
\hline Elaborar a proposta de forma detalhada, consistente e com autoria & 20 & $64,5 \%$ \\
\hline Elaborar uma proposta com autoria, pois já elaboro proposta consistente & 7 & $22,5 \%$ \\
\hline Total de respostas & 31 & $100 \%$ \\
\hline
\end{tabular}

A maioria tem dificuldade em elaborar proposta detalhada, consistente e com autoria, ou seja, quase o todo em que se constitui uma proposta de intervenção. Enquanto isso, $22,5 \%$ não têm problemas com consistência argumentativa, mas sim com a autoria importante fator para o ENEM, já cobrado logo na competência 2. Em temas objetivos, a tendência é que candidatos escrevam textos clichês, porque não conseguem sair da argumentação óbvia e isso envolve também a proposta de intervenção.

Elaborei no questionário duas perguntas abertas, as quais envolvem a opinião pessoal dos candidatos acerca do próprio desempenho e das aulas de redação. Serão colocadas aqui as respostas mais interessantes e relacionadas ao objetivo deste artigo.

\section{Pergunta 3}

Para você, o que falta no seu texto para tirar nota mil?

Algumas respostas:

"Menos erros de concordância e uma intervenção precisa, ou seja, com todos os agentes sociais e suas propostas detalhadas."

"Elaborar proposta de intervenção mais consistente e com um maior número de agentes." 
“O tema muitas vezes é um dificultante. Muitas vezes há desconhecimento para 'achar' argumentos e intertextualidades."

\section{Pergunta 4}

O que mais falta nas aulas de redação?

"Ênfase em intervenções possíveis para escrever na redação do ENEM."

"Debates acerca do tema a fim de desenvolver o senso crítico necessário para a resolução de questões contemporâneas exigidas pelo ENEM.”

"Sugestão de livros, textos, algumas fontes de referência para conseguirmos uma bagagem cultural maior para elaborar os textos com mais facilidade."

Tais respostas permitem a reflexão de que os alunos têm mais dificuldade em saber o que escrever, porque, quando faltam intertextualidades, falta também senso crítico - crucial em um texto de caráter argumentativo. Esse fato também se reflete na proposta de intervenção, no sentido de que o participante deve inserir nela agentes e ações detalhadas: quem vai fazer e como será feito? Sem bagagem cultural necessária, não há meios de se construir um texto de fato consistente.

O repertório cultural se torna, então, fator essencial na escrita. Os candidatos muitas vezes não conseguem obter tal repertório por falta de leitura e interesse nas notícias atuais. Em um mundo onde se valoriza tudo o que já está pronto, não se encontra necessidade e curiosidade suficientes para criticar e conhecer aquilo que nos cerca. Isso se confirma com os resultados da pesquisa, em que muitos candidatos alegaram que faltam nas aulas de redação mais debates sobre o tema proposto.

\section{CONSIDERAÇÕES FINAIS}

Após entender melhor as dificuldades dos candidatos na prova de redação, é possível propor algumas sugestões que visem a ajudar o candidato a elaborar a proposta de intervenção. Ela começa já no desenvolvimento com a problematização, ou seja, o participante primeiro planeja quais serão os problemas abordados no desenvolvimento do texto para então construir uma intervenção completa.

Para aqueles que mais têm dificuldades, vale selecionar no mínimo três problemas a partir do tema. Isso se torna plausível na prova do ENEM, pelo fato de os temas serem sempre objetivos e de cunho social.

Por exemplo, no tema de 2015 "A persistência da violência contra a mulher na sociedade brasileira", há um leque de possibilidades. Como problematização, pode-se 
mencionar a visão patriarcal existente sobre a mulher numa sociedade supostamente evoluída; o papel da mídia como formadora de opiniões sexistas, principalmente em novelas; a ineficácia da justiça brasileira em proteger as mulheres da violência.

Após a seleção da problemática é que é possível elaborar intervenção completa. Para cada problema selecionado, haverá uma solução plausível e, para ter sucesso nessa etapa, cabe selecionar um agente para cada solução. Ainda com relação ao exemplo do tema de 2015, na escolha de quem realizará as ações da intervenção, pode-se escolher os próprios responsáveis envolvidos nos problemas: cidadão, mídia e governo.

No entanto, não basta selecionar agentes, também cabe inserir no texto ações detalhadas. Nessa parte é que o candidato pode inovar e atingir sua autoria. Ao detalhar como cada ação será feita, ele pode até mesmo inserir intertextualidades e especificações, como se ele fosse de alguma forma um agente também, responsável por resolver aquela situação.

Para ilustrar, continuemos com o tema de 2015. Usando a mídia como agente, uma ação possível para essa seria a transmissão de ficções engajadas - novelas, por exemplo, as quais abordem problema da violência de gênero - a fim de que a visão patriarcal seja aos poucos mudada. Com relação ao agente "governo", é válido especificar um órgão responsável pelo cumprimento das leis ou pelo atendimento a casos de violência contra a mulher, por exemplo as delegacias da mulher. Além disso, também é uma possibilidade mencionar a Lei Maria da Penha nessa parte do texto, a fim de demonstrar bagagem cultural. Ao fim da intervenção, escrever um benefício - o que acontecerá de benéfico para a sociedade caso a intervenção proposta seja bem-sucedida - também dá à redação o detalhamento esperado pela banca.

Todas essas sugestões parecem interessantes, mas como um professor poderá preparar seu aluno para a prova de redação do ENEM, em vista das dificuldades relatadas? Uma boa estratégia é usar os eixos temáticos - educação; meio ambiente; justiça social; direitos humanos; ética social e direitos da criança e do adolescente - como base para a criação de possíveis temas da prova e para os debates em sala de aula.

Outro fator relevante é que, com a consciência dos eixos temáticos, o candidato estudará previamente intertextualidades relacionadas a eles, de forma que esteja preparado para a proposta da prova. Por exemplo, se estudar o Estatuto da Criança e do Adolescente, poderá escrever sobre isso em qualquer proposta do eixo temático "direitos da criança e do adolescente". Se estudar teóricos que escreveram sobre desigualdade social, poderá produzir um texto, com mais facilidade, sobre um tema de justiça social. 
De fato, essas estratégias são um ótimo auxílio, em razão de a autoria ser algo que se consegue com bastante leitura, com a inserção de intertextualidades diversas, pois assim não há perigo de elaborar argumentação limitada ao senso comum.

\section{REFERÊNCIAS}

BAKHTIN, Mikhail. Estética da criação verbal. São Paulo. Martins Fontes, 2003.

FIORIN: José Luiz de. Introdução ao pensamento de Bakhtin. São Paulo: Ática, 2006.

FRASSON, Regina Mafalda Denardim. A intertextualidade como recurso argumentativo. Letras, Santa Maria, n. 4, p. 85-96, 1992.

$\mathrm{KOCH}$, Ingedore Vilaça \& Vanda Maria ELIAS. 2009. Ler e escrever. Estratégias de produção textual. São Paulo: Editora Contexto.

KRISTEVA, Julia. Introdução à semanálise. $2^{\mathrm{a}}$ edição. Trad. Lúcia Helena França Ferraz. São Paulo: Perspectiva, 2005.

Redação do ENEM 2016. Cartilha do participante. Disponível em: $<$ http://download.inep.gov.br/educacao_basica/enem/guia_participante/2016/manual_de_r edacao_do_enem_2016.pdf> Acesso em 10 dez. 2016. 